\title{
Root Hairs Play a Key Role in the Endophytic Colonization of Olive Roots by Pseudomonas spp. with Biocontrol Activity
}

\author{
Pilar Prieto • Elisabetta Schilirò • María Mercedes Maldonado-González • \\ Raquel Valderrama • Juan Bautista Barroso-Albarracín • Jesús Mercado-Blanco
}

Received: 14 December 2010 / Accepted: 8 February 2011 /Published online: 24 February 2011

(C) The Author(s) 2011. This article is published with open access at Springerlink.com

\begin{abstract}
The use of indigenous bacterial root endophytes with biocontrol activity against soil-borne phytopathogens is an environmentally-friendly and ecologically-efficient action within an integrated disease management framework. The earliest steps of olive root colonization by Pseudomonas fluorescens PICF7 and Pseudomonas putida PICP2, effective biocontrol agents (BCAs) against Verticillium wilt of olive (Olea europaea L.) caused by the fungus Verticillium dahliae Kleb., are here described. A gnotobiotic study system using in vitro propagated olive plants, differential fluorescent-protein tagging of bacteria, and confocal laser scanning microscopy analysis have been successfully used to examine olive roots-Pseudomonas spp. interactions at the single-cell level. In vivo simultaneous visualization of PICF7 and PICP2 cells on/in root tissues enabled to discard competition between the two bacterial strains during root colonization. Results demon-
\end{abstract}

Pilar Prieto and Elisabetta Schilirò are joint first authors.

P. Prieto

Departamento de Mejora Genética,

Instituto de Agricultura Sostenible, Consejo Superior de

Investigaciones Científicas (CSIC),

Alameda del Obispo s/n, Apdo. 4084,

14080 Córdoba, Spain

E. Schilirò • M. M. Maldonado-González •

J. Mercado-Blanco $(\square)$

Departamento de Protección de Cultivos,

Instituto de Agricultura Sostenible, Consejo Superior de

Investigaciones Científicas (CSIC),

Alameda del Obispo s/n, Apdo. 4084,

14080 Córdoba, Spain

e-mail: jesus.mercado@ias.csic.es

R. Valderrama $\cdot$ J. B. Barroso-Albarracín Departamento de Biología Experimental, Universidad de Jaén, 23071 Jaén, Spain strated that both BCAs are able to endophytically colonized olive root tissues. Moreover, results suggest a pivotal role of root hairs in root colonization by both biocontrol Pseudomonas spp. However, colonization of root hairs appeared to be a highly specific event, and only a very low number of root hairs were effectively colonized by introduced bacteria. Strains PICF7 and PICP2 can simultaneously colonize the same root hair, demonstrating that early colonization of a given root hair by one strain did not hinder subsequent attachment and penetration by the other. Since many environmental factors can affect the number, anatomy, development, and physiology of root hairs, colonization competence and biocontrol effectiveness of BCAs may be greatly influenced by root hair's fitness. Finally, the in vitro study system here reported has shown to be a suitable tool to investigate colonization processes of woody plant roots by microorganisms with biocontrol potential.

\section{Introduction}

A significant portion of the beneficial microbiota inhabiting the rhizosphere of plants is constituted by bacteria. Some of them, qualified as plant growth-promoting rhizobacteria (PGPR), have been studied as highly competitive root colonizers [1]. Furthermore, their potential as biocontrol agents (BCAs) against soil-borne plant pathogens of many important crops makes PGPR application an attractive strategy within a sustainable agriculture framework [2-4].

Root colonization by soil-resident bacteria can be limited to the root surface, but some of them can also gain entrance into the root tissues establishing as non-deleterious endophytes [5]. Beneficial endophytic bacteria are of particular interest in plant diseases biocontrol because of their ability 
to internally colonize plant tissues, posing the advantage to be adapted to the ecological niche where biocontrol mechanism(s) may be deployed. Understanding processes enabling bacteria to penetrate, colonize, and endure within root tissues is a key knowledge to improve their efficiency as long-term, effective BCAs against soilborne phythopathogens.

Verticillium wilts, caused by the soil-borne fungal pathogen Verticillium dahliae Kleb., are important plant vascular diseases responsible of significant yield losses in many economically-relevant crops worldwide [6]. For instance, Verticillium wilt of olive (Olea europaea L.) (VWO) is nowadays considered one of the most serious biotic menaces for this woody crop throughout its range of cultivation. Within a framework of sustainable, integrated disease management strategy, the use of BCAs has been proposed as a complementary action to control Verticillium wilts, including VWO [7]. Effective biological control of Verticillium wilts has been reported, but most of the studies have predominantly focused on herbaceous hosts and involved only a small number of fungi or bacteria genera [8-11]. The genus Pseudomonas, which comprises diverse well-studied plant growth-promoting and biocontrol strains [12], is an important and often dominant resident group found in the rhizosphere of diverse Verticillium-susceptible crops [13]. Selected strains of fluorescent pseudomonads have been also demonstrated as effective BCAs against Verticillium wilts [13-15].

Pseudomonas fluorescens PICF7 and Pseudomonas putida PICP2 strains are natural colonizers of olive roots. In vitro antagonism against $V$. dahliae and effective biocontrol of VWO in nursery-produced olive plants (cvs. Picual and Arbequina) have been previously demonstrated for these strains $[14,16]$. Further investigations have shown the ability of strain PICF7 to endophytically colonize the roots of olive plants cv. Arbequina under non-gnotobiotic experimental conditions [17]. Moreover, early colonization by strain PICF7 at both the epidermis and cortex of intact olive roots seems to be essential to prevent VWO onset and development in nursery-produced plants [16].

The use of gnotobiotic systems to investigate root colonization offers the advantage to reduce rhizosphere competence effects $[18,19]$ and to diminish environmental fluctuations affecting the population of the microorganism under study [20]. In addition, these systems are attractive because of the reduced space and time needed for plant growth and manipulation, particularly in the case of woody plants. In vitro plant systems have been successfully used to examine rhizosphere colonization processes by PGPR [2123]. Most of these studies have been conducted in herbaceous plants. Therefore, there is an important gap in our knowledge on how, when, and where beneficial bacteria colonize and establish on/in roots of woody species, as a prerequisite to further understand how biocontrol and/or plant growth promotion mechanisms are subsequently deployed.

The objectives of this research were: (1) to unravel the earliest colonization events of olive roots by two VWO biocontrol Pseudomonas spp. strains and the preferred sites to start endophytic colonization; (2) to determine possible competition between the two bacterial strains when colonizing olive roots; and (3) to verify the suitability of an in vitro study system to study Pseudomonas spp.-olive interactions.

\section{Materials and Methods}

Pseudomonas spp. Strains, Bacterial Tagging with Fluorescent Proteins, and Inocula Production

Strains of two different Pseudomonas species, P. fluorescens PICF7 and P. putida PICP2 [14], were used in this study. Culture conditions and inoculum preparation of $P$. fluorescens PICF7 carrying plasmids pMP4655 [harboring the enhanced green fluorescent protein (EGFP) marker] or pMP4662 [harboring the red fluorescent protein (RFP) marker] [22] have been previously described [17]. Culture conditions for P. putida PICP2 strain were the same as for PICF7. EGFP tagging of PICP2 was carried out by electroporation [24]. The presence of plasmid pMP4655 in selected PICP2 transformants was checked by plasmid DNA purification using the FavorPrep Plasmid DNA Extraction Mini Kit (Favorgen Biotech Corp., Taiwan), following manufacturer's instructions, and by subsequent EcoRI (New England Biolabs) restriction analysis.

The final bacterial cell density in inocula used for rootdip inoculation of olive plants (see below) was determined both spectrophotometrically $\left(\mathrm{OD}_{600 \mathrm{~nm}}\right)$ and by counting viable tetracycline resistant $\left(\mathrm{Tc}^{\mathrm{R}}\right)$ colonies. For single root inoculation with either EGFP-tagged PICF7 or EGFPtagged PICP2, inoculum densities were $1 \times 10^{8}$ and $1.1 \times$ $10^{8} \mathrm{cfu} \mathrm{ml}^{-1}$, respectively. Cell densities of inocula for simultaneous inoculation with differentially tagged bacteria were: (1) $2.1 \times 10^{6}$ and $2.3 \times 10^{6} \mathrm{cfu} \mathrm{m}^{-1}$ for the mixture of EGFP-tagged PICF7 and RFP-tagged PICF7, respectively, and (2) $2.3 \times 10^{6}$ and $2.5 \times 10^{6} \mathrm{cfu} \mathrm{ml}^{-1}$ for the mixture of RFP-tagged PICF7 and EGFP-tagged PICP2, respectively.

Plant Material and In Vitro Propagated Olive Plants Conditions

Olive (Olea europaea L., cv. Manzanilla) plants were generated from seeds provided by the World Bank of Germoplasm (IFAPA, Córdoba, Spain) and germinated under in vitro conditions as previously reported [25]. Plants 
production, propagation, and culturing conditions were also previously described [25]. Plants were propagated on a micronutrients-rich solid medium (DKW-2) [26].

Seedlings were grown in the dark at $13^{\circ} \mathrm{C}$ for 15 days in an embryos medium which consisted of MS medium [27] containing only one third concentration of macronutrients and sucrose [28] and without hormones [29]. Then, plantlets were transferred to a Sylvania Gro-Lux lighting chamber (Sylvania, Westfield, IN, USA) at $25^{\circ} \mathrm{C}$ and $16 \mathrm{~h}$ light $\left(130-140 \mu \mathrm{mol} \mathrm{m}{ }^{-2} \mathrm{~s}^{-1}\right)$ for another 8 weeks. After that, plants were transferred to a DKW-2 medium [26] and were grown in the same conditions for six additional weeks.

Assessment of Olive Roots Colonization by Pseudomonas spp. Using In Vitro Propagated Plants and a Gnotobiotic Study System

Two different bioassays were conducted using fluorescently tagged Pseudomonas spp. derivatives and 3-month in vitro propagated olive plants, (1) to elucidate the root colonization process of two different biocontrol Pseudomonas strains, P. fluorescens PICF7 and P. putida PICP2, and (2) to investigate possible bacteria interaction when in vitro olive plants were co-inoculated simultaneously either with RFP- and GFP-tagged P. fluorescens PICF7 or with RFP-tagged $P$. fluorescens PICF7 and EGFP-tagged $P$. putida PICP2.

A hundred and ten in vitro olive plants were used in total for the two bioassays. In both experiments in vitro olive plants were carefully uprooted from the agar-based medium under sterile conditions. The plant root systems were dipped for $15 \mathrm{~min}$ in bacterial suspensions containing EGFP-tagged $P$. fluorescens PICF7, EGFP-tagged P. putida PICP2, a mixture of EGFP- and RFP-tagged $P$. fluorescens PICF7, or a mixture of RFP-tagged P. fluorescens PICF7 and EGFP-tagged $P$. putida PICP2 (for final cell densities in different inocula, see above). Plants were then individually transferred to a solid medium containing $6 \mathrm{~g} \mathrm{~L}^{-1}$ bacteriological agar (Oxoid, Hampshire England) and incubated in an I-36LL Controlled Environmental Chamber (Percival Scientific, Perry, IA) at $25^{\circ} \mathrm{C}, 60-80 \%$ relative humidity, and $16 \mathrm{~h}$ light $\left(115 \mu \mathrm{mol} \mathrm{m}{ }^{-2} \mathrm{~s}^{-1}\right)$. When in vitro olive plants were used as controls for checking the presence of native autofluorescence, root systems were dipped in a $10 \mathrm{mM} \mathrm{MgSO}{ }_{4} \cdot 7 \mathrm{H}_{2} \mathrm{O}$ solution.

To elucidate the colonization process of in vitro olive plants by P. fluorescens PICF7 and P. putida PICP2, 65 plants were used in a first bioassay: 25 plants were inoculated with EGFP-tagged PICF7, another 25 plants inoculated with EGFP-tagged PICP2 strains, and, finally, 15 plants were used as controls. Bacterial cell densities in inocula have been indicated above. Twenty plants were examined for each Pseudomonas spp. treatment, one plant every day from 1 to 10 days after bacterization (DAB) and then one plant every 3 days until 40 DAB. Control plants were analyzed at $1,8,22$, and 40 DAB.

To assess possible competence between Pseudomonas spp. strains during the colonization process (bacteria interaction bioassay), 45 in vitro propagated olive plants were manipulated as follows: 15 plant were co-inoculated with a mix of RFP- and EGFP-tagged P. fluorescens PICF7 cells and another 15 plants were co-inoculated with a mix of RFP-tagged $P$. fluorescens PICF7 and EGFP-tagged $P$. putida PICP2. Final bacterial cell densities in inocula (see above) were similar to the ones used during the first bioassay. Finally, ten in vitro olive plants were inoculated with EGFP-tagged $P$. fluorescens PICF7 as positive control of the olive root colonization process, and five additional plants were just dipped into the $\mathrm{MgSO}_{4} \cdot 7 \mathrm{H}_{2} \mathrm{O}$ solution to check for native autofluorescence. Plants from each treatment were sampled every day from 1 to 7 DAB. Thereafter, one plant from each treatment was analyzed every 3 days until the end of the experiment. Control plants were analyzed 1,7 , and $31 \mathrm{DAB}$.

\section{Isolation of Bacteria from Plant Roots}

To determine bacterial population sizes present on/in roots of bacteria-inoculated olives along the experiments, root systems of randomly selected plants were uprooted, carefully washed in sterile water, and briefly dried on sterile filter paper. Root tissue samples $(100 \mathrm{mg})$ were ground under sterile conditions in $2 \mathrm{ml}$ of $10 \mathrm{mM}$ $\mathrm{MgSO}_{4} \cdot 7 \mathrm{H}_{2} \mathrm{O}$. Serial dilutions of the macerates were plated onto Luria-Bertani (LB) agar plates (three plates per dilution) amended with Tc $\left(20 \mathrm{mg} \mathrm{L}^{-1}\right)$ and incubated at $25^{\circ} \mathrm{C}$ for $48 \mathrm{~h}$. Then, $\mathrm{Tc}^{\mathrm{R}}$ bacterial colonies were counted, and bacterial populations were expressed as colony-forming units per gram of fresh root tissues. For each sampling time-point, three bacterized plants and two non-bacterized plants were analyzed. In the co-inoculation bioassay, PICP2 and PICF7 $\mathrm{Tc}^{\mathrm{R}}$ colonies were distinguished by their different colony morphologies when grown on LB agar plates. In addition, a fair number of EGFP-tagged PICP2 and RFP-tagged PICF7 $\mathrm{Tc}^{\mathrm{R}}$ colonies were further checked by measuring the differential fluorescence of bacterial cells suspensions from each colony using a Synergy HT analyzer (BioTek Instruments Inc., USA).

Root Sectioning and Time-Course Confocal Laser Scanning Microscopy Detection

Preparation of olive tissues samples for microscopy detection of fluorescently tagged Pseudomonas spp. has been previously described in detail $[16,17]$. At least three different roots from each plant were sectioned under 
distilled water using a Vibratome Series 1000plus (TAAB Laboratories Equipment Ltd, Aldermaston, UK). Three dimensional (3-D) vibratome root tissue sections (20$50 \mu \mathrm{m}$ thick) containing two to three cell layers were use to visualize fluorescently tagged $P$. fluorescens PICF7 and P. putida PICP2 strains over $40 \mathrm{DAB}$. Confocal laser scanning microscopy (CLSM) stacks were obtained using an Axioskop 2 MOT microscope (Carl Zeiss Inc., Jena $\mathrm{GmbH}$, Germany) equipped with a krypton and an argon laser and supported by the Laser Scanning System LSM5 PASCAL software (Carl Zeiss Inc.). For microscope data analysis, the Zeiss LSM Image Browser version 4.0 program (Carl Zeiss Inc.) was used. Bacterial colonization of olive roots was analyzed from 3-D confocal data stacks. Projections from adjacent confocal optical sections were made for composing images shown in this study. Final figures were processed with Photoshop 4.0 software (Adobe Systems Inc., San Jose, CA).

\section{Results}

Root Hairs Are Required for the Efficient Root Colonization of In Vitro Propagated Olive Plants by $P$. fluorescens PICF7

The use of fluorescently tagged bacteria and CLSM enabled to demonstrate that $P$. fluorescens PICF7 effectively colonize roots of in vitro propagated olive plants under gnotobiotic conditions. The entire colonization process by an EGFP-tagged PICF7 derivative was recorded, from the very earliest stages (bacteria adhesion to root hair surface) to the colonization of the intercellular spaces within the cortex of the differentiation zone (Fig. 1a-e). The olive root rhizoplane was rapidly colonized by EGFP-tagged PICF7 cells. Bacteria were predominantly detected on the olive root differentiation zone and were clearly observed on the surface of olive root hairs from 2 DAB (Fig. 1a). Observations showed that PICF7 cells were attached along the whole root hair surface, mostly at random distribution, displaying no preferred site for the external colonization of these modified plant root cells.

Internal colonization of root hairs by EGFP-tagged PICF7 was detected as early as 3 DAB and full-colonized root hairs were observed 4 DAB (Fig. 1b). However, inner colonization of root hairs did not occur frequently and only a low number (less than $2 \%$ ) of olive root hairs were internally colonized by PICF7. Internal colonization of root hairs by PICF7 cells showed a diverse pattern and bacteria could be detected either as single cells or clusters (colonies) attached to inner membrane structures of the root hair (Fig. 1c, arrowed). A recurrent observation was that EGFP- tagged bacteria progressively colonized the whole root hair until they reach the basal region of the cell 6 DAB (Fig. 1d). PICF7 was always detected in the intercellular spaces of the olive root cortex tissue, never inside cells, from 7 DAB (Fig. 1e). No significant changes in sampled plants were observed up to the end of the bioassay ( 40 $\mathrm{DAB}$, data not shown). It is worth mentioning that continuous, overlapped events of root hairs adhesion/ colonization and intercellular root-cortex colonization by EGFP-tagged PICF7 took place during the bioassay. Finally, the population size of PICF7 on/in "Manzanilla" roots throughout the experiment, and under the in vitro growth conditions assayed, decreased over time. Thus, the number of $\mathrm{Tc}^{\mathrm{R}}$ colonies recovered from macerated root tissue of three plants sampled at 8 DAB greatly fluctuated from plant to plant $\left(7 \times 10^{6}, 4 \times 10^{7}\right.$, and $\left.1 \times 10^{8} \mathrm{cfu} \mathrm{g}^{-1}\right)$. However, the number of viable bacteria scored on/in roots of plants sampled at 22 DAB decreased approximately two orders of magnitude in comparison with the original inoculum density, although PICF7 populations seemed to be stabilized among plants at this sampling time-point $(7 \times$ $10^{6}, 8 \times 10^{6}$, and $\left.8.9 \times 10^{6} \mathrm{cfu}^{-1}\right)$. No $\mathrm{Tc}^{\mathrm{R}}$ colonies were recovered from the un-inoculated plants (controls) sampled at 8 or $22 \mathrm{DAB}$.

Colonization of Olive Root Hairs by P. fluorescens PICF7 Is a Consequence of Multiple Ingress Events

In order to elucidate whether the internal colonization of a given olive root hair by $P$. fluorescens PICF7 is the result of a single colonization event by one PICF7 cell followed by its multiplication inside the root hair or, alternatively, a consequence of multiple adhesion/entrance events, in vitro propagated olive plants were inoculated with a mixture of RFP- and EGFP-tagged PICF7 cells. CLSM imagery showed that, on the one hand, colonies formed by both fluorescently tagged derivatives were detected on the root epidermis, sharing the same colonization site (Fig. 1f). However, one of the tagged populations often predominated over the other, suggesting that one cell (for instance, EGFPtagged PICF7) colonized a particular epidermal spot earlier than a RFP-tagged PICF7 cell (Fig. 1f, arrowed). On the other hand, simultaneous internal colonization of root hairs by RFP- and EGFP-tagged PICF7 was also detected (Fig. 1g), as previously described for the single EGFPtagged PICF7 bacterization experiment. Most of the observed fully colonized root hairs contained a mixed population of EGFP- and RFP-tagged bacteria. However, some root hairs were predominantly colonized by one of the two fluorescently tagged PICF7 derivatives (data not shown). This result demonstrated that entrance of one bacterial cell into the root hair did not prevent further adhesion and penetration events by other bacteria. 

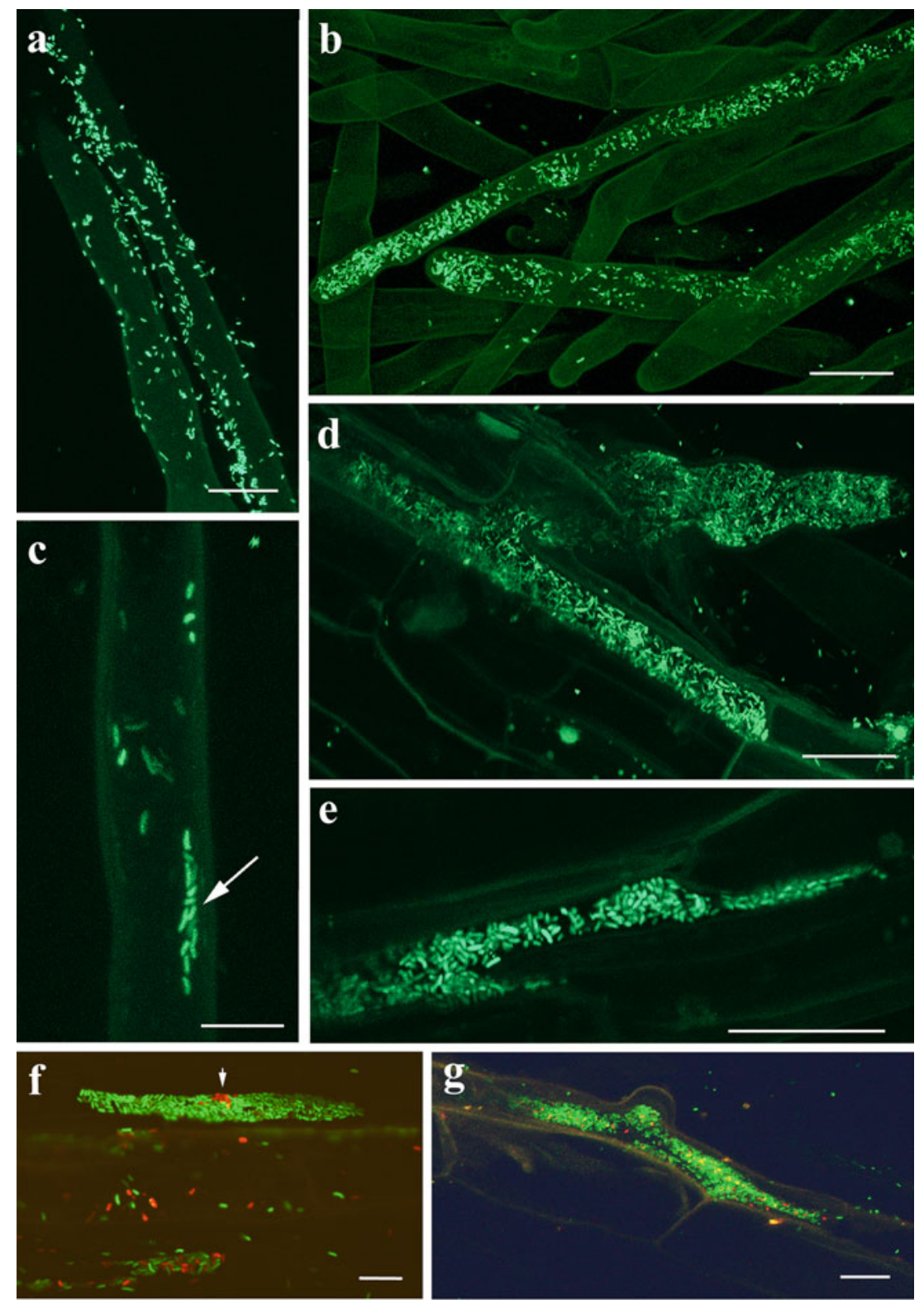

Figure 1 CLSM images of the time-course colonization processes of in vitro micropropagated olive cv. Manzanilla roots by EGFP- and RFP-tagged P. fluorescens PICF7. Confocal analysis was performed on 3-4-cm-long root longitudinal vibratome sections to show surface (a, f) and inner (b-e, g) PICF7 colonization. Single confocal optical sections are shown in $\mathbf{c}$ and $\mathbf{e}-\mathbf{f}$. Images in $\mathbf{a}, \mathbf{b}, \mathbf{d}$ and $\mathbf{g}$ are projections of 25 adjacent confocal optical sections. Focal step between confocal optical sections was $0.5 \mu \mathrm{m}$. a Surface EGFPtagged PICF7 colonization of two root hairs, 2 DAB. b Detection of EGFP-tagged PICF7 inside two root hairs, 4 DAB. Several noncolonized root hairs are also shown. c Confocal optical sections of an

The Biocontrol P. putida PICP2 Strain Uses Root Hairs as Main Door for Endophytic Colonization of Olive Roots

The same study system and methodological approach were used to elucidate whether the root colonization process described for $P$. fluorescens PICF7 could be similar for

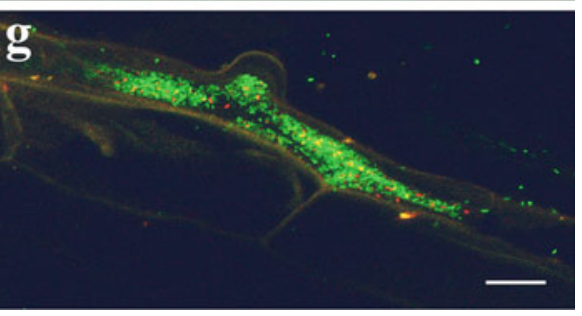

internally EGFP-tagged PICF7 colonized root hair, 5 DAB. Some bacteria are observed as single cells or as a colony (arrowed) attached to the inner surface of the root hair. $\mathbf{d}$ An entirely colonized root hair by EGFP-tagged PICF7, 6 DAB. e Intercellular colonization of the cortical tissue of the root differentiation zone by EGFP-tagged PICF7 cells, 7 DAB. f Simultaneous detection of EGFP-tagged PICF7 and RFP-tagged PICF7 on the root surface of in vitro propagated olive plants, 2 DAB. g An entire trichoblast simultaneously colonized by EGFP- and RFP-tagged P. fluorescens 5 DAB. Scale bar represents $20 \mu \mathrm{m}$ in all panels, except in $\mathbf{a}$ where it represents $50 \mu \mathrm{m}$ and $\mathbf{f}$ and $\mathbf{g}$ where it represents $10 \mu \mathrm{m}$

other indigenous bacteria of olive roots. To do so, P. putida PICP2 was successfully transformed by electroporation with plasmid pMP4655 (EGFP). Restriction analysis confirmed the presence of plasmid pMP4655 in several transformants. The expected green fluorescence of a selected P. putida PICP2 transformant $\left(\mathrm{Tc}^{\mathrm{R}}\right)$ was validated 
by epifluorescence of a bacterial cell suspension prepared from a culture grown on a LB agar plate. Stability of plasmid pMP4655 was assessed by continuous subculturing (maintaining an exponential growth rate) of the selected transformant in liquid $\mathrm{LB}$ under no selective pressure (without $\mathrm{Tc}$ ) during 6 days at $25^{\circ} \mathrm{C}$. No plasmid loss was detected $\left(100 \%\right.$ colonies were $\left.\mathrm{Tc}^{\mathrm{R}}\right)$ after that period of time. Presence of pMP4655 plasmid was verified in several $\mathrm{Tc}^{\mathrm{R}}$ colonies at the end of this experiment by restriction analysis. Consequently, an EGFP-tagged $P$. putida PICP2 derivative was confirmed as a valid tool to visualize olive root colonization by this strain.

The colonization process of in vitro olive plants by EGFP-tagged PICP2 was analyzed by CLSM as described above for PICF7-tagged cells. Representative root colonization events are summarized in Fig. 2. PICP2 cells were early observed surrounding and/or attached to the surface of root hairs but preferentially at the tip (Fig. 2a). Subsequently, EGFP-tagged PICP2 cells could be detected not only in the interior of root hairs (3 DAB) but also predominantly situated at the apex (Fig. 2b). This pattern of internal colonization of root hairs tips by EGFP-tagged PICP2 was repeatedly recorded (Fig. 2c). Events of attachment of PICP2 cells on the surface of root hairs were continuously detected during the whole bioassay, even though a root hair was already internally colonized (Fig. 2d, white arrowed). Interestingly enough, a narrowing of an internal membranous structure occupying most of the root hair and including EGFP-tagged PICP2 cells was also observed (Fig. 2d, red arrowed). This suggested that bacteria were wrapped within an organelle, likely the vacuole. This bacteria confinement was also observed during the colonization of olive root hairs by $P$. fluorescens PICF7 (Fig. 1g).

Once EGFP-tagged PICP2 internally colonized the tip of a root hair, bacteria gradually progressed down to the base of the cell. Indeed, a gradient of bacteria concentration was repeatedly detected inside root hairs, the number of bacteria being usually higher in the tip (Fig. 2e). Complete internal colonization of root hairs by EGFP-tagged PICP2 cells was first observed 6 DAB (Fig. 2f). The proportion of olive root hairs colonized by $P$. putida PICP2 was estimated to be very low (less than $2 \%$ ), as previously observed for $P$. fluorescens PICF7. CLSM analysis showed that fluorescently tagged PICP2 cells finally colonized the intercellular spaces within the cortex region of the root differentiation zone at 10 DAB (Fig. 2g). PICP2 cells were never observed inside cortical cells or invading the vascular tissue.

The colonization events of in vitro olive roots by the EGFP-tagged $P$. putida PICP2 described here have been repetitively observed in an overlapped fashion throughout the duration of the bioassay, and bacteria persisted on/in roots up to the end of the experiment (40 DAB). Finally, the size of EGFP-tagged PICP2 populations was confirmed by counting the number of $\mathrm{Tc}^{\mathrm{R}}$ colonies recovered from macerated root tissues of three different plants at two time-points. As mentioned for PICF7, PICP2 populations on/in roots decreased over time approximately one order of magnitude from $8 \mathrm{DAB}\left(5 \times 10^{7}, 7.5 \times 10^{7}\right.$, and $1 \times$ $\left.10^{8} \mathrm{cfu} \mathrm{g}^{-1}\right)$ to $22 \mathrm{DAB}\left(2.3 \times 10^{6}, 4.4 \times 10^{6}\right.$, and $5 \times$ $\left.10^{6} \mathrm{cfu}^{-1}\right)$. No $\mathrm{Tc}^{\mathrm{R}}$ colonies were scored from the uninoculated (controls) plants.

Olive Roots Are Simultaneously Colonized by Both Beneficial P. fluorescens PICF7 and P. putida PICP2

A bioassay was conducted to assess possible competence between P. fluorescens PICF7 and P. putida PICP2 during the colonization process of roots of in vitro propagated olive plants. Both strains were detected at the same time on root hairs surface 1 DAB (data not shown). Simultaneous internal colonization of root hairs of in vitro olive plants by both bacterial species was detected 3 DAB (Fig. 3a). Fully colonized root hairs, either by RFP-tagged PICF7 or by EGFP-tagged PICP2, were observed. Remarkably, however, both bacteria were also able to internally colonize the same root hair (Fig. 3a, arrowed). Therefore, three different types of colonized root hairs were detected: those one predominantly occupied by one strain or the other and those containing a balanced population of both strains, which was the most frequent situation (Fig. 3b). The number of root hairs internally colonized was very small throughout the duration of the experiment, as previously observed for single inoculation experiments. Eventually, both Pseudomonas spp. could be detected colonizing the intercellular spaces of the cortex in the root differentiation zone (Fig. 3c).

Despite root hairs could be colonized predominantly by one of the strains or by a mixture of both, PICP2 and PICF7 populations $\left(\mathrm{Tc}^{\mathrm{R}}\right.$ colonies) recovered from macerated root tissue of three different plants have considerably decreased at $35 \mathrm{DAB}$, although they showed to be balanced in the same plant $\left(2.6 \times 10^{3}, 3.7 \times 10^{3}\right.$, and $8.6 \times 10^{3} \mathrm{cfu} \mathrm{g}^{-1}$ for $P$. fluorescens PICF7 and $2.5 \times 10^{3}, 3.1 \times 10^{3}$, and $7 \times$ $10^{3} \mathrm{cfu}^{-1}$ for $P$. putida PICP2). These results not only demonstrated an apparent absence of competence between P. fluorescens PICF7 and P. putida PICP2 in colonizing root hairs of in vitro propagated olive plants but also confirmed the persistence of both strains over time and the equilibrium of their populations on/in the same colonized olive root system along the bioassay.

The study system developed here enabled to observe very precise events taking place in vivo during the colonization process of olive root hairs by PICF7 and PICP2 and at the single-cell level. Firstly, continuous 

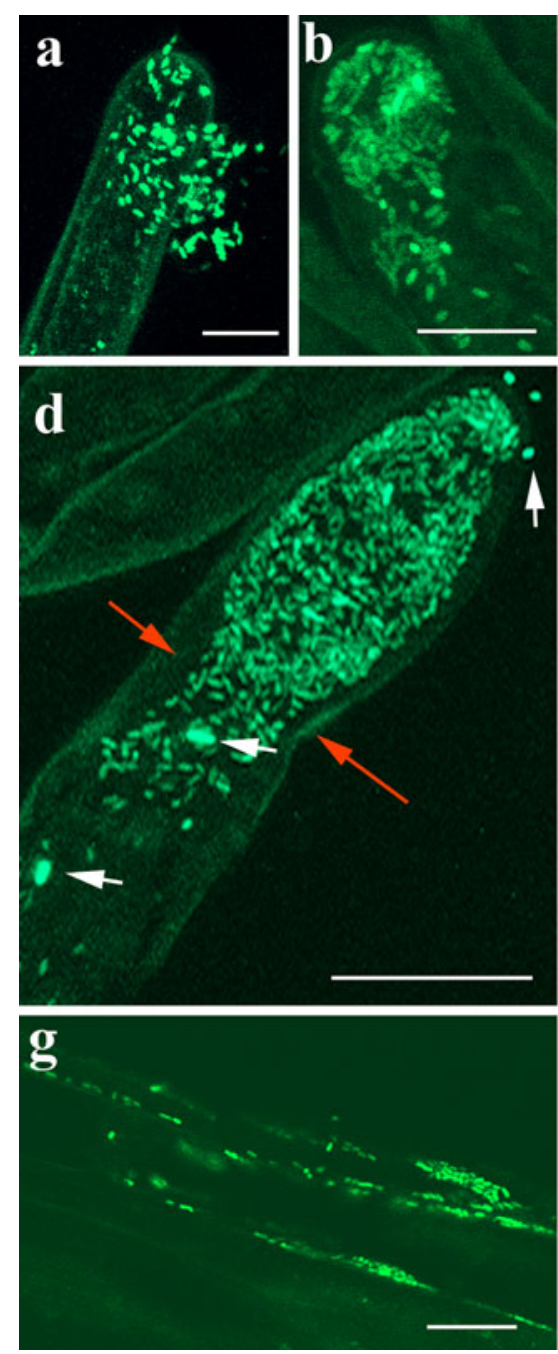

Figure 2 Time-course colonization processes of in vitro micropropagated olive cv. Manzanilla roots by EGFP-tagged $P$. putida PICP2. Confocal analysis was performed on 3-4-cm-long root longitudinal vibratome sections to show surface (a) and inner (b-g) PICP2 colonization. A single confocal optical section is shown in $\mathbf{g}$. Images in a-e are projections of 20 confocal optical sections, and image in $\mathbf{f}$ is a projection of 40 adjacent confocal optical sections. Focal step between confocal optical sections was $0.5 \mu \mathrm{m}$. a Surface colonization of a root-tip hair by EGFP-tagged PICP2, 2 DAB. b Detection of EGFP-PICP2 inside the root-tip hair, 3 DAB. A higher concentration of EGFP-tagged PICP2 cells was observed in the apex of the root-tip hair. $\mathbf{c}$ Internal colonization of the apical region of two root hairs by EGFP-tagged PICP2, 5 DAB. Several bacteria were also

CLSM analysis of defined sites of an olive root clearly demonstrated the migration of tagged bacteria within a root hair (Fig. 3d). In this particular case, although both Pseudomonas spp. colonized the same root hair, RFPtagged PICF7 was the predominant strain. Indeed, CLSM showed that bacteria were actively moving inside the root hair, multiplying in its interior, and progressing along the root hair quickly. The movement of bacteria from the apex to the basal zone of the root hair was verified by an increment of the number of bacteria within the inset
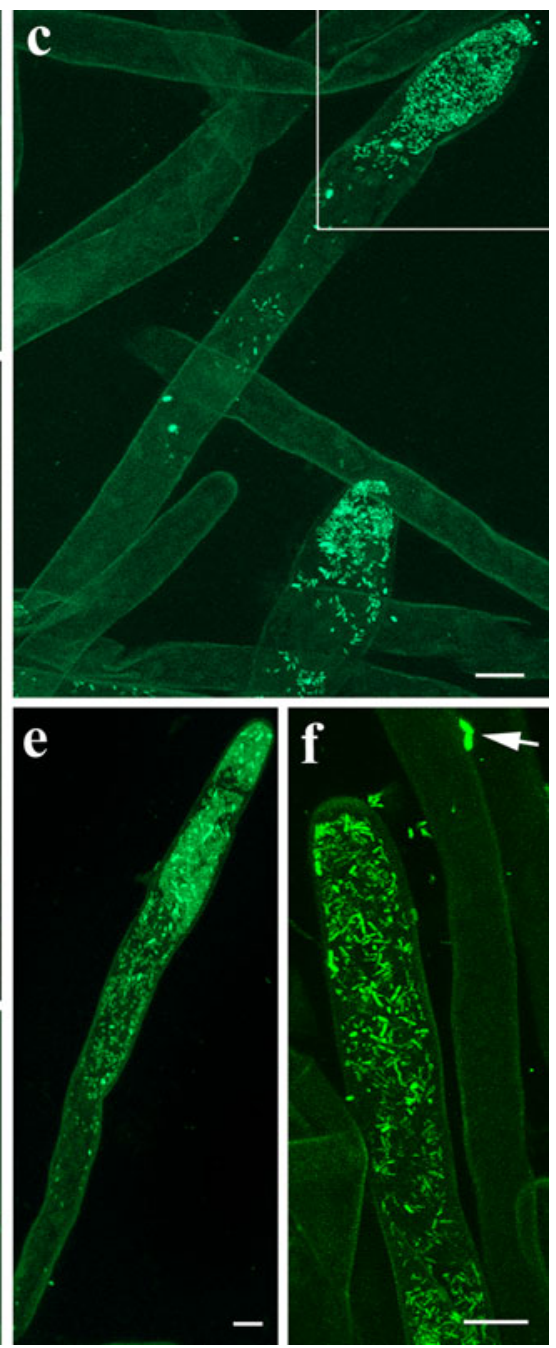

detected in the intermediate zone of the root hair. Non-EGFP-tagged PICP2 colonized root hairs are also shown. d Magnification of the area inset in c. Bacteria were continuously attached to the surface of the root hair (arrowed). e Migration of EGFP-tagged PICP2 through the root hair cell from the tip to the base of the root hair cell. Bacteria concentration decreased along the root, 5 DAB. $\mathbf{f}$ Detection of EGFPtagged PICP2 distributed homogeneously inside a root hair entirely colonized 6 DAB. EGFP-tagged PICP2 was continuously detected attached to the root hairs surface during the whole time-course experiment (arrowed). g Intercellular colonization of the cortical tissue in the root differentiation zone by EGFP-tagged PICP2, 10 DAB. Scale bars represent $10 \mu \mathrm{m}$ in all panels

(rectangle), used as a reference of bacterial movement, only 15 min after the first CLSM projection was taken (Fig. 3d). The progression of both strains inside the root hair continued $30 \mathrm{~min}$ after the first capture, already surpassing the rectangle area (Fig. 3d). Secondly, bacteria (EGFP-tagged PICP2 in this case) were continuously attaching and colonizing the root hair's surface, regardless this root hair was already internally colonized (Fig. 3d, arrowed). Thus, bacteria were metabolically active along the bioassay, with little disturbance during the manipulation 


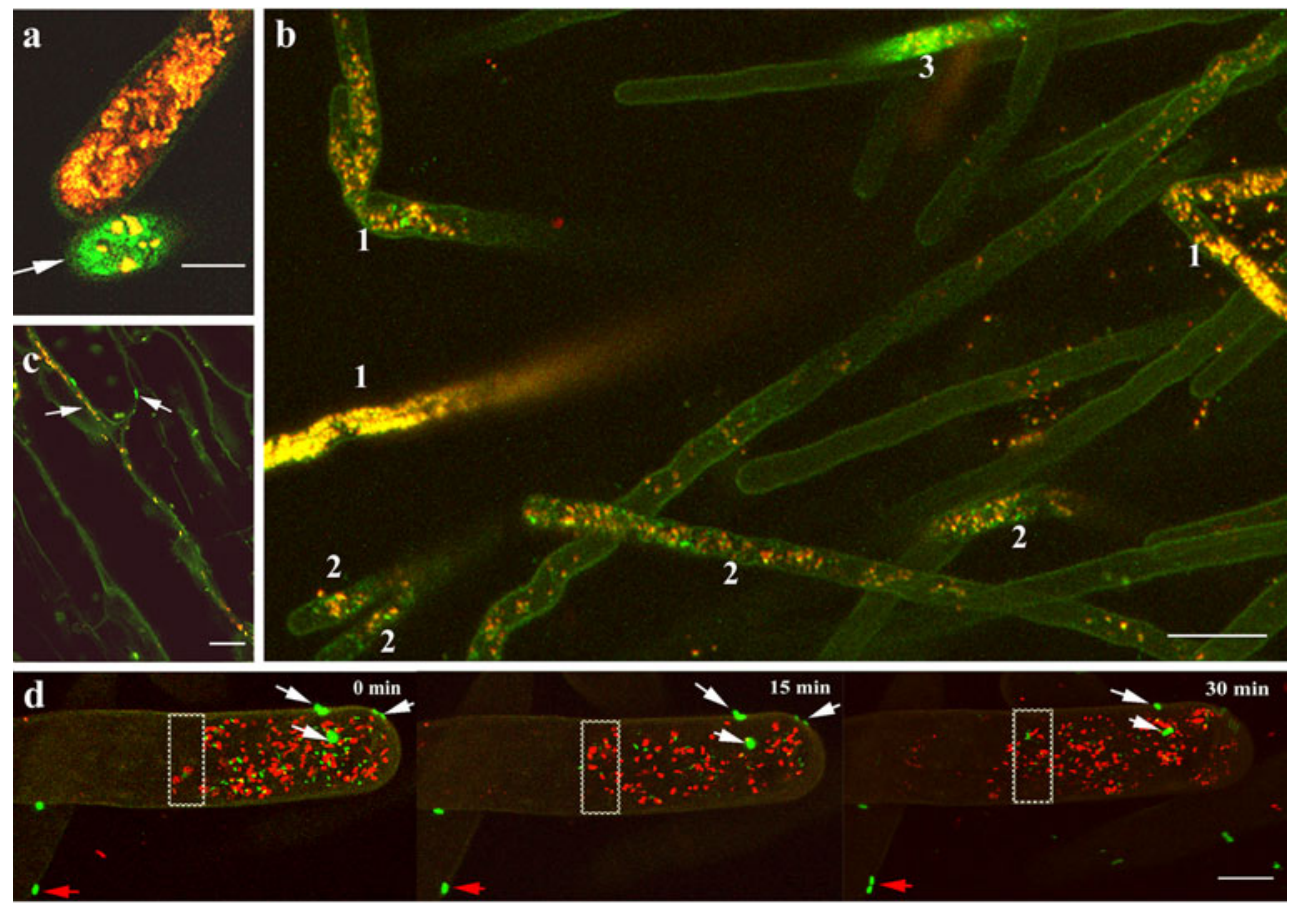

Figure 3 Simultaneous colonization of in vitro olive cv. Manzanilla root hairs by EGFP-tagged $P$. putida PICP2 and RFP-tagged $P$. fluorescens PICF7. Single confocal optical sections are shown in a and $\mathbf{c}$. Images in $\mathbf{b}$ and $\mathbf{d}$ are projections of 15 and 50 confocal optical sections, respectively. Focal step between confocal optical sections was $0.5 \mu \mathrm{m}$. a Single confocal optical section of two transversal root hairs of an in vitro olive plant simultaneously colonized by EGFPtagged PICP2 and RFP-tagged PICF7, 3 DAB. Simultaneous localization of both Pseudomonas spp. strains inside a root hair is observed (arrowed). b Simultaneous colonization of an in vitro propagated olive plant rhizoplane by Pseudomonas EGFP-tagged PICP2 (green) and RFP-tagged PICF7 (orange in the image), 5 DAB. Three different colonized root hairs are detected, root hairs mostly colonized by RFP-tagged PICP2 (1), root hairs colonized equally by EGFP-tagged PICP2 and RFP-tagged PICF7 bacteria (2) and a root hair mostly colonized by EGFP-tagged PICP2, although some RFPtagged PICF7 are also detected (3). c Intercellular colonization of the cortical tissue of the differentiation root zone by EGFP-PICP2 and RFP-PICF7 simultaneously, 10 DAB. d Dynamics of the colonization

of the sampled tissue, displaying changes in their position, and adhering to or disappearing from the root hair surface during the time this area was submitted to CLSM analysis. Remarkably, bacteria were also observed going through cell division meanwhile attached to the root hair surface (Fig. 3d, red arrows).

\section{Discussion}

Non-efficient root colonization by BCAs is considered a limiting factor for effective biocontrol. Indeed, long-term root colonization by beneficial microorganisms is crucial to achieve successful crop protection against soil-borne phythopathogens [30]. While knowledge on traits of process inside a root hair by the two biocontrol (EGFP-tagged PICP2 and RFP-tagged PICF7) strains at three different time-points. The first CLSM capture (time $[t]=0$ ) showed RFP-tagged PICF7 (predominant population) and EGFP-tagged PICP2 cells internally colonizing a root hair, mainly at the distal region of the root hair. The drawn rectangular inset, here used as a reference to assess bacteria movement, showed several (three) RFP-tagged PICF7 and one EGFP-tagged PICP2 cells in the interior of this area. Several EGFP-tagged PICP2 bacteria attached to the surface of the root hair are also arrowed. Displacement of EGFP-tagged PICP2 and RFP-tagged PICF7 cells towards the trichoblast basal zone was observed 15 min later. A higher number of bacteria could be counted within the inset. An increment in the size of one EGFP-tagged PICP2 visualized on the root hair surface was also detected at this stage (red arrow). At $t=30 \mathrm{~min}$, bacteria were not only detected inset but also further left. One of the EGFP-tagged PICP2 attached to the surface of one root hair (red arrow) completed cell division during the time this area was continuously monitored by CLSM (30 min). Scale bar represents $10 \mu \mathrm{m}$ in all panels except in c where it represents $20 \mu \mathrm{m}$

Pseudomonas spp. involved in root colonization has been gathered during the last decade [12], and strategies to enhance root-colonizing abilities of beneficial Pseudomonas strains have also been reported [31, 32], little is known on how root colonization by beneficial Pseudomonas strains does occur. This work describes the use of an in vitro study system to investigate root colonization processes of olive plants roots by non-deleterious, indigenous Pseudomonas spp. Gnotobiotic systems have been earlier employed to examine root colonization by $P$. fluorescens strains in both herbaceous [21] and woody [33] species. These study systems have also been proved valuable to determine endophytic colonization of different plant species tissues by diverse bacterial genera [34, 35]. The use of axenic systems has many advantages in plant/microbe 
interaction studies, although extrapolation of results obtained under gnotobiotic conditions to greenhouse or field conditions has to be made with the necessary caution $[33,36]$. Besides the reduction in space and time required for plant growth and manipulation, particularly in the case of woody plants, soilless study systems greatly reduce interferences caused by diverse (a)biotic factors present in soils. We demonstrate here that the use of a gnotobiotic study system is valid to assess the endophytic lifestyle of $P$. fluorescens PICF7 in olive roots, with no significant differences to the colonization process previously observed under non-gnotobiotic conditions [16, 17]. In addition, the in vitro system facilitated the imaging of very detailed rootbacteria interaction events obtained by CLSM. Interestingly, population dynamics of the introduced bacteria was rather similar under both experimental conditions and PICF7 population sizes on/in roots of sampled plants decreased by approximately two orders of magnitude at $21 \mathrm{DAB}$ (non-gnotobiotic, [17]) or $22 \mathrm{DAB}$ (gnotobiotic, in vitro plants, this study). This clearly suggested that the population of introduced bacteria decreased over time until reaching equilibrium and that the reduction observed could not simply due to competition with the microbiota present in plants grown under non-gnotobiotic conditions.

In the present study, P. putida PICP2 has proved to endophytically colonize in vitro propagated "Manzanilla" olive roots as well. Therefore, both olive-indigenous, biocontrol strains displayed similar root colonization patterns, including endophytic lifestyle, when colonizing olive roots. Remarkably, we have identified root hairs as key structures for olive roots' endophytic colonization by these two Pseudomonas spp. The importance of root hairs for plant root colonization by beneficial bacteria other than the well-studied symbiotic Rhizobiaceae group [37] has not been investigated in detail. Root hairs are single, specialized extensions of epidermal cells which increase root surface area facilitating physical anchorage to substrates and providing a large interface to absorb nutrients and water [38]. Studies on root hairs have been mostly focused on their physiology, morphology, and cell differentiation genetics [39-42]. Nevertheless, these specialized root epidermal structures may play also a major role in plantmicrobe interactions, not fully understood though. Thus, colonization of root hairs in rice (Oryza sativa L.) by Burkholderia kururiensis [35] or in Pinus halepensis by $P$. fluorescens [33] has been reported using different microscopy approaches. However, reports on colonization of root hairs by Pseudomonas spp. mostly refer to attachment or colonization of bacteria to the surface [33, 43, 44]. Recently, internal colonization of Arabidopsis thaliana and tomato (Lycopersicum esculentum Mill) root hairs by fluorescently labeled Escherichia coli and Saccharomyces cerevisae (non-pathogenic and non-symbiotic microorgan- isms), has been demonstrated [45]. Our results have demonstrated internal root hairs colonization by indigenous Pseudomonas spp. in olive using different plant growth conditions (gnotobiotic and non-gnotobiotic) and in several independent bioassays. Therefore, internal colonization of root hairs and its key involvement in endophytic colonization by beneficial soil bacteria other than rhizobia could be a common phenomenon. Finally, many soil factors such as soil acidity, soil humidity, aluminum and potassium levels, etc., influence root hairs density, length, physiology, and development [46, 47]. Moreover, under soil drought conditions, some PGPR may stimulate cellular division in roots and increase root hairs number [48]. This further leads to enhanced water and nutrient uptake by plant roots, especially from deeper soil layers [49]. Accordingly, it is necessary to be acquainted with soil factors influencing root hairs that may affect bacteria-root hair interactions and, subsequently, biocontrol and/or plant growth promotion abilities deployed by bacteria.

Endophytism can be considered as a universal phenomenon and probably all plants carry endophytic bacteria [5]. Endophytic populations of beneficial Pseudomonas spp. have been detected in many plant species [12], and we have demonstrated this lifestyle for two native olive roots Pseudomonas spp. In the present study, we showed for the first time that endophytic colonization of olive roots by these BCAs is a consequence of multiple bacterial entrance events, either from the same strain or from different Pseudomonas spp. Moreover, a previously colonized root hair did not hamper further bacterial penetration. In addition, no response from the plant seemed to take place to hinder multiple bacterial entries. Despite both Pseudomonas spp. used root hairs as main entrance for olive roots endophytic colonization, the colonization pattern by P. putida PICP2 seemed to be even more localized (root hair tips) than the one observed for P. fluorescens PICF7 (random attachment). Regarding to this, two different $P$. fluorescens strains on barley (Hordeum vulgare L.) [50] or Pseudomonas stutzeri strains on rice [51] have been also observed colonizing root hairs tips. However, internal root hair colonization was never reported in these studies unlike results presented here.

No plant cell response at the microscopic level has been detected as a consequence of olive root hairs colonization by Pseudomonas spp. Full-colonized root hairs by PICF7, PICP2, or PICF7/PICP2 did not differ in shape or size to non-colonized root hairs. The well-known root hair morphological changes to colonization by rhizobia described in legumes [37] have not been observed either. Little is known about how root cells react to nonpathogenic or non-symbiotic bacteria. Recently, the responses to the endophytic root colonization by $E$. coli and yeasts have been studied [45]. These authors reported that the interaction of these microbes with Arabidopsis 
roots induced plant cell wall-like outgrowth and altered expression of genes involved in cell wall modification. Whether similar responses are taking place in the endophytic colonization of olive roots by non-pathogenic Pseudomonas spp. remains to be elucidated.

A space between the root hair cell wall and bacteria confined within a membranous-like structure was often visible in our study. In Arabidopsis, mature root hairs include a large central vacuole throughout their length [52]. Regarding to this, we think that our observations point to bacteria likely confined within the vacuole in colonized olive root hairs. Although we have clearly demonstrated internal olive root hairs colonization by Pseudomonas spp., how bacteria eventually reach the intercellular spaces of the cortical root tissue still remains unclear. What has been undoubtedly demonstrated by CLSM is the persistence of PICF7 and PICP2 cells in the intercellular spaces of the root cortex always until the end of our bioassays. This is clearly in contrast with the recent observation that non-pathogenic or non-symbiotic microbes rapidly disappeared from inner root tissues of Arabidopsis, presumably because they are degraded by the plant [45].

In summary, fluorescently tagged bacteria, CLSM, and in vitro propagated olive plants provide a powerful approach to study olive-bacteria interaction. The importance of root hairs for olive roots colonization by beneficial Pseudomonas spp. has been clearly demonstrated, root hairs being the key for an efficient endophytic colonization. Moreover, it has been proved for the first time that internal colonization of olive root hairs is the result of multiple bacteria penetration events, regardless a root hair had been previously colonized. In view of our results, if root hairs can be considered as a main door for beneficial bacteria to gain entrance into root tissues, we suggest that previous studies reporting root hair colonization by bacteria only at the surface in other plant species should be revised.

Acknowledgments This research was supported by grants P07-CVI02624 (Proyecto de Excelencia, Junta de Andalucía, Spain) and AGL2009-07275 (Spanish Ministerio de Ciencia e Innovación, cofinanced by FEDER of the UE). We thank A. Valverde for technical assistance. Authors also want to acknowledge Prof. Antonio Martín for his support and use of the CLSM and vibratome facilities, and Dr. Elena Prats for the possibility of using the Synergy HT analyzer. We are also indebted to Dr. Guido Bloemberg for the gift of plasmids pMP4655 and pMP4662.

Open Access This article is distributed under the terms of the Creative Commons Attribution Noncommercial License which permits any noncommercial use, distribution, and reproduction in any medium, provided the original author(s) and source are credited.

\section{References}

1. Lugtenberg BJJ, Kamilova F (2009) Plant-growth-promoting rhizobacteria. Annu Rev Microbiol 63:541-556
2. Gerhardson B (2002) Biological substitutes for pesticides. Trends Biotechnol 20:338-343

3. Compant S, Duffy B, Nowak J, Clement C, Ait Barka E (2005) Use of plant growth-promoting bacteria for biocontrol of plant diseases: principles, mechanisms of action, and future prospects. Appl Environ Microbiol 71:4951-4959

4. Höfte M, Altier N (2010) Fluorescent pseudomonads as biocontrol agents for sustainable agricultural systems. Res Microbiol 161:464-471

5. Rosenblueth M, Martínez-Romero E (2006) Bacterial endophytes and their interactions with hosts. Mol Plant-Microbe Interact 19:827-837

6. Klosterman SJ, Atallah ZK, Vallad GE, Subbarao KV (2009) Diversity, pathogenicity and management of Verticillium species. Annu Rev Phytopathol 47:39-62

7. López-Escudero FJ, Mercado-Blanco J (2011) Verticillium wilt of olive: a case study to implement an integrated strategy to control a soil-borne pathogen. Plant Soil. doi:10.1007/s11104-010-0629-2

8. Madi L, Katan T, Katan J, Henis Y (1997) Biological control of Sclerotium rolfsii and Verticillium dahliae by Talaromyces flavus is mediated by different mechanisms. Phytopathology $87: 1054-1060$

9. Tjamos EC, Tsitsigiannis DI, Tjamos SE, Antoniou P, Katinakis P (2004) Selection and screening of endorhizosphere bacteria from solarised soils as biocontrol agents against Verticillium dahliae of solanaceous hosts. Eur J Plant Pathol 110:35-44

10. Garmendia I, Goicoechea N, Aguirreolea J (2004) Effectiveness of three Glomus species in protecting pepper (Capsicum annuum L.) against Verticillium wilt. Biol Control 31:296-305

11. Erdogan O, Benlioglu K (2010) Biological control of Verticillium wilt on cotton by the use of fluorescent Pseudomonas spp. under field conditions. Biol Control 53:39-45

12. Mercado-Blanco J, Bakker PAHM (2007) Interactions between plants and beneficial Pseudomonas spp.: exploiting bacterial traits for crop protection. Antonie van Leeuwenhoek 92:367-389

13. Berg G, Roskot N, Steidle A, Eberl L, Zock A, Smalla K (2002) Plant-dependent genotypic and phenotypic diversity of antagonistic rhizobacteria isolated from different Verticillium host plants. Appl Environ Microbiol 68:3328-3338

14. Mercado-Blanco J, Rodríguez-Jurado D, Hervás A, Jiménez-Díaz RM (2004) Suppression of Verticillium wilt in olive planting stocks by root-associated fluorescent Pseudomonas spp. Biol Control 30:474-486

15. Debode J, Maeyer KD, Perneel M, Pannecoucque J, Backer GD, Höfte M (2007) Biosurfactants are involved in the biological control of Verticillium microsclerotia by Pseudomonas spp. J Appl Microbiol 103:1184-1196

16. Prieto P, Navarro-Raya C, Valverde-Corredor A, Amyotte SG, Dobinson KF, Mercado-Blanco J (2009) Colonization process of olive tissues by Verticillium dahliae and its in planta interaction with the biocontrol root endophyte Pseudomonas fluorescens PICF7. Microbial Biotechnol 2:499-511

17. Prieto P, Mercado-Blanco J (2008) Endophytic colonization of olive roots by the biocontrol strain Pseudomonas fluorescens PICF7. FEMS Microbiol Ecol 64:297-306

18. Leifert C, Morris CE, Waites WM (1994) Ecology of microbial saprophytes and pathogens in tissue culture and field-grown plants: reasons for contamination problems in vitro. Critical Rev Plant Sci 13:139-139

19. Holland MA, Polacco JC (2003) PPFMs and other covert contaminants: is there more to plant physiology than just plant? Annu Rev Plant Physiol Plant Mol Biol 45:197-209

20. Sturz AV, Nowak J (2000) Endophytic communities of rhizobacteria and the strategies required to create yield enhancing associations with crops. Appl Soil Ecol 15:183-190

21. Chin-A-Wong TFC, de Priester W, van der Bij AJ, Lugtenberg BJJ (1997) Description of the colonization of a gnotobiotic tomato 
rhizosphere by Pseudomonas fluorescens biocontrol strain WCS365, using scanning electron microscopy. Mol PlantMicrobe Interact 10:79-86

22. Bloemberg GV, Wijfjes AHM, Lamers GEM, Stuurman N, Lugtenberg BJJ (2000) Simultaneous imaging of Pseudomonas fluorescens WCS365 populations expressing three different autofluorescent proteins in the rhizosphere: new perspectives for studying microbial communities. Mol Plant-Microbe Interact 13:1170-1176

23. Gamalero E, Lingua G, Tombolini R, Avidano L, Pivato B, Berta G (2005) Colonization of tomato root seedling by Pseudomonas fluorescens 92rkG5: spatio-temporal dynamics, localization, organization, viability, and culturability. Microbial Ecol 50:289-297

24. Choi KH, Kumar A, Schweizer HP (2006) A 10-min method for preparation of highly electrocompetent Pseudomonas aeruginosa cells: application for DNA fragment transfer between chromosomes and plasmid transformation. J Microbiol Meth 64:391-397

25. Valderrama R, Corpas FJ, Carreras A, Gómez-Rodríguez MV, Chaki M, Pedrajas JR et al (2006) The dehydrogenase-mediated recycling of NADPH is a key antioxidant system against salt-induced oxidative stress in olive plants. Plant Cell Environ 29:1449-1459

26. Driver JA, Kuniyuki AH (1984) In vitro propagation of paradox walnut root-stock. Hort Sci 19:507-509

27. Murashige T, Skoog F (1962) A revised medium for rapid growth and bio-assay with tobacco tissue culture. Physiol Plant 15:473497

28. Rugini E (1986) Olive (Olea europaea L.). In: Bajaj YPS (ed) Biotechnology in agriculture and forestry. I. Trees. Springer, Berlin, pp 253-267

29. Monnier M (1990) Zygotic embryo culture. In: Bhojwani SS (ed) Plant tissue culture: applications and limitations. Elsevier, Amsterdam, pp 366-393

30. Lugtenberg B, Leveau J (2007) Biocontrol of plant pathogens: principles, promises and pitfalls. In: Pinton R, Nannipieri ZVP (eds) The Rhizosphere: biochemistry and organic substances at the soil-plant interface, 2nd edn. CRC Press/Taylor \& Francis Group, Boca Raton, pp 267-296

31. de Weert S, Dekkers LC, Kuiper I, Bloemberg GV, Lugtenberg BJJ (2004) Generation of enhanced competitive root-tipcolonizing Pseudomonas bacteria through accelerated evolution. J Bacteriol 186:3153-3159

32. Kamilova F, Validov S, Azarova T, Mulders I, Lugtenberg B (2005) Enrichment for enhanced competitive plant root tip colonizers selects for a new class of biocontrol bacteria. Environ Microbiol 7:1809-1817

33. Rincón A, Ruíz-Díez B, García-Fraile S, Lucas García JA, Fernández-Pascual M, Pueyo JJ, de Felipe MR (2005) Colonisation of Pinues halepensis roots by Pseudomonas fluorescens and interaction with the ectomycorrhizal fungus Suillus granalatus. FEMS Microbiol Ecol 51:303-311

34. Shishido M, Breuil C, Chanway CP (1999) Endophytic colonization of spruce by plant growth-promoting rhizobacteria. FEMS Microbiol Ecol 29:191-196

35. Mattos KA, Pádua VLM, Romeiro A, Hallack LF, Neve BC, Ulisses TMU, Barros CF, Todeschini AR, Previato JO, Mendonça-Previato L (2008) Endophytic colonization of rice
(Oryza sativa L.) by the diazotrophic bacterium Burkholderia kururiensis and its ability to enhance plant growth. Annais Acad Bras. Ciencias 80:477493

36. Lugtenberg BJJ, Dekkers L, Bloemberg GV (2001) Molecular determinants of rhizosphere colonization by Pseudomonas. Annu Rev Phytopathol 39:461-490

37. Kijne JW (1992) The Rhizobium infection process. In: Stacey G, Burris RH, Evans HJ (eds) Biological nitrogen fixation. Chapman and Hall, New York, pp 349-398

38. Peterson RL, Farquhar ML (1996) Root hairs: specialized tubular cells extending root surfaces. Bot Rev 62:2-33

39. Dolan L, Costa S (2001) Evolution and genetics of root hair stripes in the root epidermis. J Exp Bot 52:413-417

40. Knight MR (2007) New ideas on root hair growth appear from the flanks. Proc Natl Acad Sci 104:20649-20650

41. Ishida T, Kurata T, Okada K, Wada T (2008) A genetic regulatory network in the development of trichomes and root hairs. Annu Rev Plant Biol 59:365-386

42. Chaffey N (2009) Root hairs. Plant cell monographs. Ann Bot $12: 103$

43. Bianciotto V, Andreotti S, Balestrini R, Bonfante P, Perotto S (2001) Mucoid mutants of the biocontrol strain Pseudomonas fluorescens CHA0 show increased ability in biofilm formation on mycorrhizal and nonmycorrhizal carrot roots. Mol Plant Microbe Interact 14:255-260

44. Buddrus-Schiemann K, Schmid M, Schreiner K, Welzl G, Hartmann A (2010) Root colonization by Pseudomonas sp. DSMZ 13134 and impact on the indigenous rhizosphere bacterial community of barley. Microb Ecol 60:381-393

45. Paungfoo-Lonhienne C, Rentsch D, Robatzek S, Webb RI, Sagulenko E, Näsholm T, Schmidt S, Lonhienne TGA (2010) Turning the table: plants consume microbes as a source of nutrients. PLOS one 7:e11915

46. Haling RE, Richardson AE, Culvenor RA, Lambers H, Simpson RJ (2010) Root morphology, root-hair development and rhizosheath formation on perennial grass seedlings is influenced by soil acidity. Plant Soil 335:457-468

47. Römheld V, Kirkby EA (2010) Research on potassium in agriculture: needs and prospects. Plant Soil 335:155-180

48. Michiels K, Vanderleyden J, Gool V (1989) Azospirillum-plant root associations: a review. Biol Fertil Soils 8:356-368

49. Compant S, van der Heijden MGA, Sessitsch A (2010) Climate change effects on beneficial plant-microorganism interactions. FEMS Microbiol Ecol 73:197-214

50. Hansen M, Kragelund L, Nybroe O, Sörensen J (1997) Early colonization of barley roots by Pseudomonas fluorescens studied by immunofluorescence technique and confocal laser scanning microscopy. FEMS Microbiol Ecol 23:353-360

51. Rediers H, Bonnecarrére V, Rainey PB, Hamonts K, Vanderleyden J, De Mot R (2003) Development and application of a dapB-based in vivo expression technology system to study colonization of rice by the endophytic nitrogen-fixing bacterium Pseudomonas stutzeri A15. Appl Environ Microbiol 69(11):6864-6874

52. Galway ME, Heckman JW, Schiefelbein JW (1997) Growth and ultrastructure of Arabidopsis root hairs: the rhd3 mutation alters vacuole enlargement and tip growth. Planta 201(209):218 